\title{
Influence of ns-Laser Cleaning Parameters on the Removal of the Painted Layer and Selected Properties of the Base Metal
}

\author{
Xinyan $\mathrm{Li}^{1}$, Dan Wang ${ }^{1,2,3, *}$, Juming Gao ${ }^{1}$, Weiwei Zhang ${ }^{1}$, Canyang $\mathrm{Li}^{1}{ }^{1}$, Nianzheng Wang ${ }^{4}$ \\ and Yucheng Lei ${ }^{1}$ \\ 1 School of Materials Science and Engineering, Jiangsu University, Zhenjiang 212013, China; \\ 2221805084@stmail.ujs.edu.cn (X.L.); 2221905013@stmail.ujs.edu.cn (J.G.); \\ 2211805032@stmail.ujs.edu.cn (W.Z.); 3170704099@stmail.ujs.edu.cn (C.L.); yclei@ujs.edu.cn (Y.L.) \\ 2 Key Laboratory of High-end Structural Materials of Jiangsu Province, Jiangsu University, \\ Zhenjiang 212013, China \\ 3 Key Laboratory of Agricultural Machinery Equipment Remanufacturing Technology of Jiangsu Province, \\ Jiangsu University, Zhenjiang 212013, China \\ 4 Suzhou Dvellk Photo-Electricity Technology Co., Ltd., Suzhou 215000, China; nz.wang@dvellk.com \\ * Correspondence: wdd_wan@ujs.edu.cn; Tel.: +86-1885-289-9062
}

Received: 6 October 2020; Accepted: 13 November 2020; Published: 26 November 2020

\begin{abstract}
The removal of the surface paint of Q345 (Gr.B) steel, as well as microstructure and hardness of the cleaned surface were investigated. The laser source used in this study is a nanosecond pulsed Gaussian light source. The surface morphology and microstructure were characterized by a scanning electron microscope and electron back-scattered diffraction. A hardness test was used for capturing variations of the parameter of the cleaned region in comparison to the base metal. The results show that when the X-scanning speed was $1500 \mathrm{~mm} / \mathrm{s}$ and Y-moving speeds was $7 \mathrm{~mm} / \mathrm{s}$ during ns-laser cleaning, respectively, the cleaned surface was relatively flat and there was only a few small residual paint. In addition, the contents of $\mathrm{Fe}$ and $\mathrm{C}$ elements on the cleaned surface reached to $89 \%$ and $9 \%$, respectively. Moreover, the roughness was the lowest of $0.5 \mu \mathrm{m}$ through the observation of the three-dimensional topography. In addition, a fine grain layer appeared on the cleaned surface after laser cleaning at the X-scanning speeds of $500 \mathrm{~mm} / \mathrm{s}$ and $1000 \mathrm{~mm} / \mathrm{s}$. The maximum hardness of the fine grain layer was more than $400 \mathrm{HV}$, higher than the base metal.
\end{abstract}

Keywords: ns-laser cleaning; paint layer; roughness; element distribution; fine grain layer

\section{Introduction}

Structural steels, having a high fracture toughness, beneficial fundamental mechanical properties, and good weldability, are widely used in manufacturing ships, airplanes, automobiles, bridges, railways, and oil and gas pipeline industries [1-3]. For the purpose of preventing materials from rusting and improving the service life of structural parts, the surface of components is always covered in paint layer. Even so, some surfaces still need to be overhauled over a period of time, since part of the paint layers could fall off. Thus, it is necessary to remove the paint layer in order to facilitate the inspection and reinstall the paint layer [4].

At present, the commonly used methods to clean the surface paint layer include mechanical process [5], chemical stages [6], and ultrasonic methods [7] etc. Shot blasting is a common type of operation in mechanical equipment, but if the flow of impacted abrasive particles is not controlled, it will cause certain damage to the surface $[5,8,9]$. Pickling is one of the main methods in chemical cleaning. Its disadvantage is that the substrate is easily corroded and has certain pollution to the environment [6]. 
During the pickling process, the volatilization of hydrochloric acid will cause physical damage to the operator, and improper disposal of waste liquid could cause environmental pollution. In a case of ultrasonic technique, due to the limitation of the size and shape of the workplace, it is difficult to be applied it for a wide range of structures.

In comparison with typical cleaning methods, laser manner, at the following advantages such as indirect contact, environmental protection, and pollution-free, can be applied in automatic process, giving the high quality of surface [10-13]. Laser cleaning with great flexibility and precision a wide range of materials. The ultrashort laser source could offer high laser intensity and provide high precision of the microdimple geometries. A heat-affected volume would occur when the materials were ablated by the ultrashort pules. Ultrashort-laser are usually used for precision micromachining, such as vision-correction surgery. Due to the dominant multiphoton absorption and ionisation processes, the ultrashort-laser cleaning efficiency is less sensitive to the chemical composition of the contaminants, when compared with ns-lasers. In addition, ns-laser could remove large chunks of material through shock-wave destruction and damage the surrounding material [14-16]. Kumar et al. [17] estimated the threshold flux of laser peeling epoxy coating basing on the material properties. Moreover, an appropriate scanning speed process window was established to remove the paint layer. Zhao et al. [18] studied the effect of laser scanning speed, line spacing, laser power, and pulse frequency on the cleaning quality of the $50 \mu \mathrm{m}$ thick polyacrylic resin primer layer on LY12 aluminum alloy plate. The results have shown that the appropriate scanning speed and pulse frequency play an important role in improving the cleaning quality. The surface paint of aluminum-based materials was removed through changing laser power density, focus length, interaction time, absorption coefficient and other process variables [19]. In addition, a simple regression linear model was established during paint stripping. Watkins et al. [20] systematically explained the cleaning mechanism and summarized six types: ablation, vibration, vaporization, light pressure, vaporization pressure, and plasma burst. Moreover, some researches also have shown that the mechanical properties of the surface of the materials could enhance after laser cleaning. Shamsujjoha et al. [21] found that the metal matrix melted and re-solidified during the process of laser removing paint, and further the surface hardness of materials increased. Shi et al. [22] pointed out that laser cleaning could effectively remove the oxide film on the aluminum alloy surface and also easily formed a hardened layer on the surface of the Al matrix. However, there is still scant research on the quantitative analysis of the removed paint surface by changing both laser Y-moving speed and $\mathrm{X}$-scanning speed during laser cleaning.

In this paper, the paint layer on the Q345 steel is employed for the laser cleaning technology. The effect of laser X-scanning speed and Y-moving speed on the surface morphology, element distribution, and roughness is investigated. Furthermore, the hardness profile is studied.

\section{Experimental Procedure}

\subsection{Materials}

The material used was Q345 (Chinese standard), same as Gr. B (Europe standard). The chemical composition is shown in Table 1. The surface of Q345 steel in a form of sheet is shown in Figure 1. The optical microscope $(\mathrm{OM})$ image of the surface covered by the black paint layer is presented in Figure 1a, and the paint layer was distributed uniformly and densely as it was investigated by the scanning electron microscope (SEM, FEI, Hillsboro, OR, USA), Figure 1b. Figure 1 illustrates the result of energy disperse spectroscopy (EDS, FEI, Hillsboro, OR, USA) on the black paint layer. The content and distribution of elements are visible in Figure 1c. The main elements of the black paint layer were $C$, as Figure $1 \mathrm{c}, \mathrm{d}$ indicate. Moreover, a small amount of $\mathrm{O}$ was distributed on the paint layer and the content of Fe was negligible because of the appearance of the covered black paint layer, as of Figure 1e,f. 
Table 1. Chemical composition of the Q345.

\begin{tabular}{cccccccccc}
\hline C & Si & Mn & P & S & Cr & Mo & Ni & Al & Fe \\
\hline 0.21 & 0.12 & 0.96 & $<0.0005$ & 0.0026 & 0.03 & 0.01 & 0.02 & 0.04 & Bal. \\
\hline
\end{tabular}
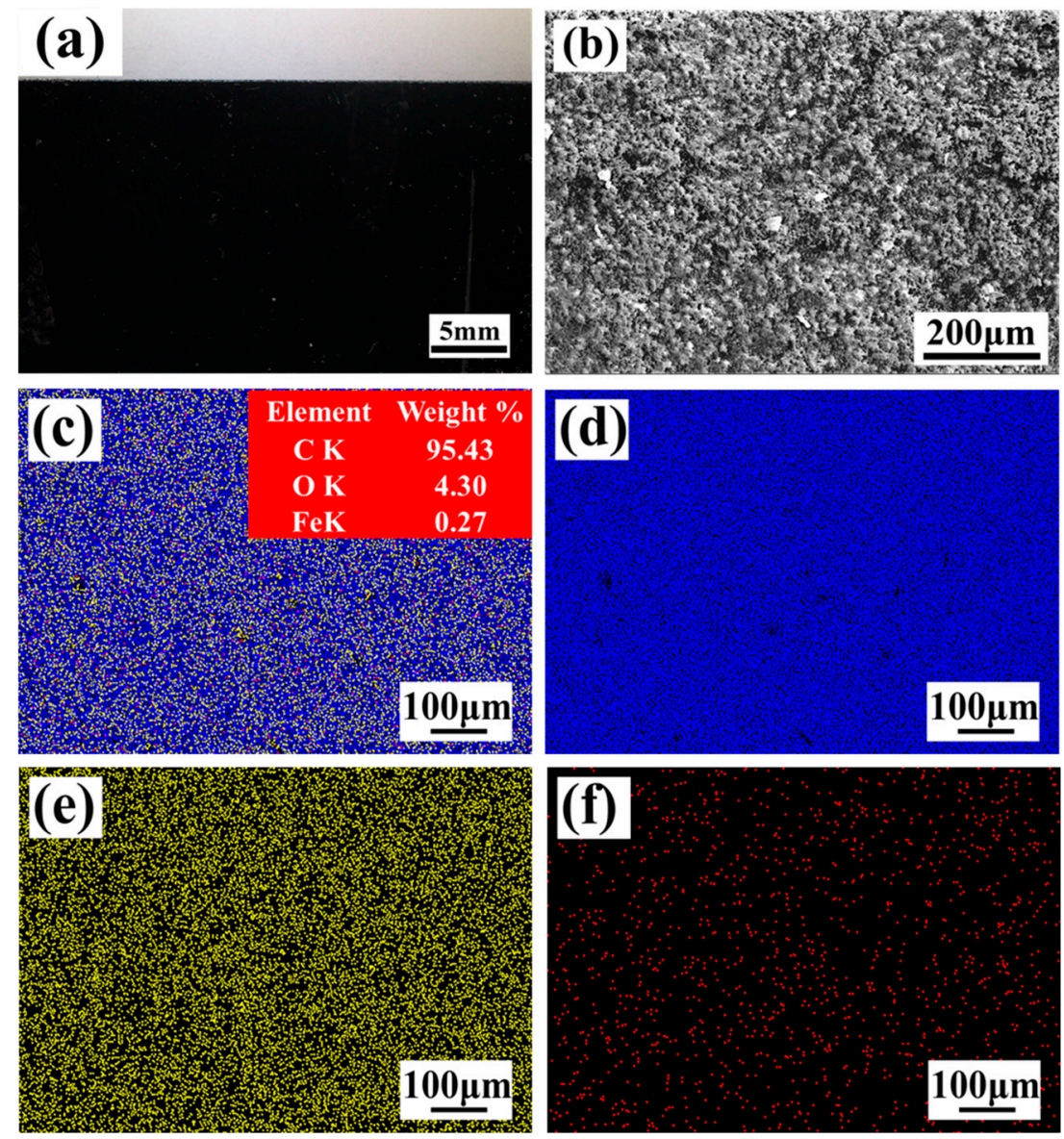

Figure 1. Morphology and EDS mapping of the black paint layer on the surface of Q345 steel. (a) OM; (b) SEM. (c) Overlay elements and percentage content; (d) C element; (e) O element; (f) Fe element.

\subsection{Experiment}

Figure 2 shows the ns-laser cleaning experimental system. The device is mainly composed of a pulsed fiber laser (Oling 200 W MOPA, Orion Laser Technology, Shenzhen, China), a hand-held laser cleaning gun, an automatic bench, an electrical control box, and a transmission system for realizing automatic and quantitative cleaning, Figure $2 \mathrm{a}$. Figure $2 \mathrm{~b}$ focuses the schematic diagram of laser cleaning operation. The materials surface contaminates, like residual paint layer, are melted and steamed by the radiation of a high frequency pulsed fiber. $X$-direction represents the direction of laser $\mathrm{X}$-scanning speed to achieve one-dimensional linear motion, and Y-direction is defined as the direction of laser Y-moving speed to achieve two-dimensional surface cleaning by combining the movement of laser scanning.

The main process parameters of laser cleaning are reported in Table 2. The pulsed fiber laser with a wavelength of $1064 \mathrm{~nm}$ was employed, and full rated power of $100 \mathrm{~W}$ was used. During cleaning, the spot diameter condensed to the material surface through the field lens is about $0.04 \mathrm{~mm}$. The laser X-scanning speed and Y-moving speed were changed from $500 \mathrm{~mm} / \mathrm{s}$ to $2000 \mathrm{~mm} / \mathrm{s}$, and from $5 \mathrm{~mm} / \mathrm{s}$ to $11 \mathrm{~mm} / \mathrm{s}$, respectively. After cleaning, a stereo-microscope, metallographic microscope, SEM, EDS, and electron back-scattered diffraction (EBSD) were used to observe the morphology, distribution of elements and microstructure of the surface and cross-section of the cleaned material. A laser scanning 
confocal microscope (OLS4100, Olympus, Tokyo, Japan) was used to perform the characterization of three-dimensional morphology and measure surface roughness. A FM-ARS900 automatic micro hardness tester (FUTURE-TECHCORP, Tokyo, Japan) was used for determining the hardness on the cross-section of the sample.

(a)



(b)

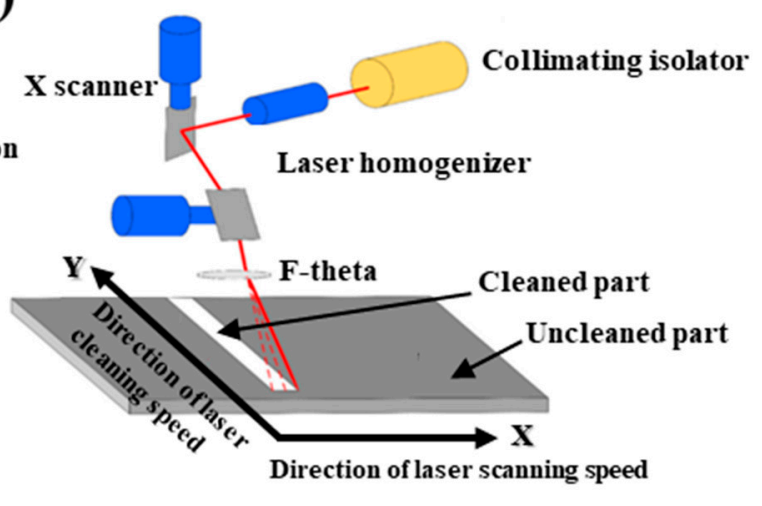

Figure 2. Laser cleaning platform system. (a) automatic laser cleaning equipment; (b) schematic diagram of cleaning operation [22].

Table 2. Main parameters of laser cleaning process.

\begin{tabular}{cc}
\hline Laser Main Parameters/Unit & Value \\
\hline X-scanning speed/(mm/s) & $500,1000,1500,2000$ \\
Y-moving speed/(mm/s) & $5,7,9,11$ \\
Average rated power/W & 100 \\
Single pulse energy/(m) & 2 \\
Repetition rate/(kHz) & 100 \\
Pulse width/(ns) & 400 \\
Spot size/(mm) & 0.6 \\
\hline
\end{tabular}

\section{Results and Discussion}

\subsection{Surface Morphology of the Cleaned Material}

In order to investigate the effect of speed parameter on Q345 surface paint laser removal, the surface morphology of the cleaned material should be observed by means of OM and SEM.

\subsubsection{The Effect of Laser X-Scanning Speed}

The effect of the laser X-scanning speed on the macro morphology of the cleaned surface of the Q345 at a laser Y-moving speed of $7 \mathrm{~mm} / \mathrm{s}$ is presented in Figure 3. When the X-scanning speed was of $500 \mathrm{~mm} / \mathrm{s}$, plenty of the lateral gullies appeared on the surface and the black between the gullies seemed to be the residual paint layer. Because of the Gaussian distribution of this laser intensity, the intensity of the middle of laser spot is higher than that of the sides. In addition to the relatively high heat input, the difference of the intensity between the middle and the sides of the laser spot could be enlarged, leading to the formation of a deep trace when a laser scanned the surface of the Q345 steel. It can also be found that the appearances of the melting and ablation were serious in selected areas, resulting in a great damage to the material, as shown in Figure 3a. When the X-scanning speed reached $1000 \mathrm{~mm} / \mathrm{s}$, the traces of the lateral gullies was reduced. It is worth nothing that the widths of the gullies were also minimized and the distribution became relatively denser. When the $\mathrm{X}$-scanning speed increased up to $1500 \mathrm{~mm} / \mathrm{s}$, the surface of the Q345 steel was completely exposed and relatively smooth. Moreover, the traces of lateral ravines were almost invisible, and also the black residue was 
less. Further increasing the speed up to $2000 \mathrm{~mm} / \mathrm{s}$, there were no traces of lateral ravines, but the granular black substances were observed on the surface.


Figure 3. The effect of laser $X$-scanning speed on the macro morphology of the cleaned surface of Q345 steel at a laser Y-moving speed of 7 mm/s. (a) 500 mm/s; (b) $1000 \mathrm{~mm} / \mathrm{s}$; (c) $1500 \mathrm{~mm} / \mathrm{s}$; (d) $2000 \mathrm{~mm} / \mathrm{s}$.

Figure 4 shows the effect of the laser X-scanning speed on the SEM morphology of the cleaned surface, and the SEM images in Figure 4 are corresponding to those in Figure 3. When the laser X-scanning speed was equal to $500 \mathrm{~mm} / \mathrm{s}$, the depth and width of the trace of the lateral gullies were relatively deeper and wider, about $190 \mu \mathrm{m}$ wide. In addition, it can be found that a complete paint layer still remained in the edge area of the scan, as shown in Figures $3 \mathrm{a}$ and $4 \mathrm{a}$. At the low X-scanning speed, the radiation per unit area is more on the surface of the material, leading to a rise in the temperature. Once the temperature is much higher than the melting points of the paint layer and the base material, it will cause the melting and vaporization of the substrate, causing surface damage [23-25]. When the X-scanning speed of the material was $1000 \mathrm{~mm} / \mathrm{s}$, the gullies became shallower and narrower, just $90 \mu \mathrm{m}$ wide, as shown in Figure $4 \mathrm{~b}$. As the X-scanning speed increased further, the traces of the gully disappeared gradually, and a relatively flat and smooth metal substrate was exposed as a whole. In addition, most of the paint on the surface of the material was removed, and there were only a few small residual particles, as shown in Figure 4c. With the X-scanning speed of $2000 \mathrm{~mm} / \mathrm{s}$, the size of the residual particles on the surface increased.

In order to confirm the specific composition of the particle, EDS was performed. Figure 4e shows the results of the EDS of the residual particles on the cleaned surface of the Q345 steel at a Y-moving speed of $7 \mathrm{~mm} / \mathrm{s}$ and a X-scanning speed of $2000 \mathrm{~mm} / \mathrm{s}$. Figure 4e indicates an enlarged SEM image of the residual particles in Figure $4 \mathrm{~d}$. It can be seen that the residual particles were uniformly distributed on the surface of the material. The main elements of the residual paint layer are $\mathrm{C}$ and $\mathrm{O}$ that are the same as that of the paint layer, as shown in Figure 4f. Thus, it can be understood that if there are plenty of large residual paint distributing on the cleaned surface, the cleaning effect is relatively poor. In contrast, the dispersed distribution of small residual paint or negligible residual paint occurred as a result of a relatively better cleaning effect. It is evident that at a low X-scanning speed, the paint on the surface of the material could be completely peeled off, or maybe the laser can damage the material. In addition, the paint could not be removed well at a high X-scanning speed. Appropriate X-scanning 
speed $(1500 \mathrm{~mm} / \mathrm{s})$ has a significant impact on the realization of laser cleaning of the surface paint layer of the material.
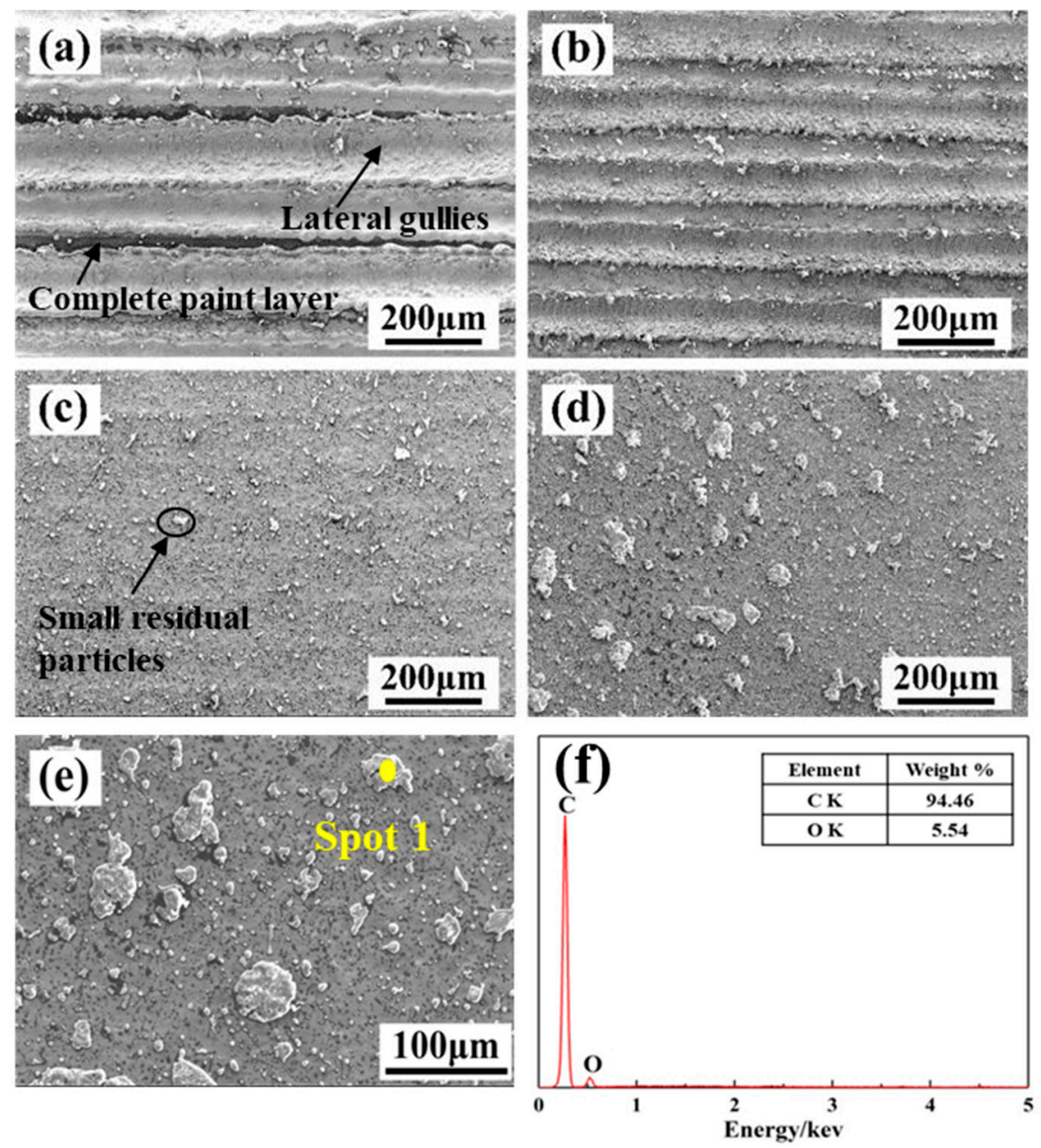

Figure 4. The effect of laser X-scanning speed on the micro-morphology (SEM and EDS) of the paint layer on the surface of Q345 steel when the laser Y-moving speed is $7 \mathrm{~mm} / \mathrm{s}$. (a) $500 \mathrm{~mm} / \mathrm{s} ;$; b $1000 \mathrm{~mm} / \mathrm{s}$; (c) $1500 \mathrm{~mm} / \mathrm{s}$; (d) $2000 \mathrm{~mm} / \mathrm{s}$; (e) enlarged SEM image; (f) the result of the point scanning of the residual particles.

\subsubsection{The Effect of Laser Y-Moving Speed}

The effect of laser Y-moving speed on the macro morphology of the cleaned Q345 steel surface at a laser X-scanning speed of $1500 \mathrm{~mm} / \mathrm{s}$ are presented in Figure 5. When the Y-moving speed was of $5 \mathrm{~mm} / \mathrm{s}$, it could be found that some areas of the material were melted and ablated seriously, and the ablated dark brown appeared on the surface, Figure 5a. When the Y-moving speed reached $7 \mathrm{~mm} / \mathrm{s}$, the paint was removed well and the surface was relatively flat in, as shown in Figure 5b. If, the Y-moving speed reached $9 \mathrm{~mm} / \mathrm{s}$ and $11 \mathrm{~mm} / \mathrm{s}$, some residual paints were observed between the gullies of the surface, as shown in Figure $5 c$,d.

The effect of the laser Y-moving speed on the SEM morphology of the cleaned surface, and the SEM images (Figure 6) are corresponding to those in Figure 5. When the Y-moving speed has taken $5 \mathrm{~mm} / \mathrm{s}$, the material was melted seriously and the trace of the lateral gullies was observed, as shown in Figure $6 \mathrm{a}$. As the Y-moving speed increased up to $7 \mathrm{~mm} / \mathrm{s}$, the surface was relatively flat and there were only a few small residual particles, as shown in Figure $6 \mathrm{~b}$. When the Y-moving speed was more than $9 \mathrm{~mm} / \mathrm{s}$, the action time of the laser radiation on the surface became short, leading to the appearance of the more remained paint layer, as shown in Figure $6 c, d$. 

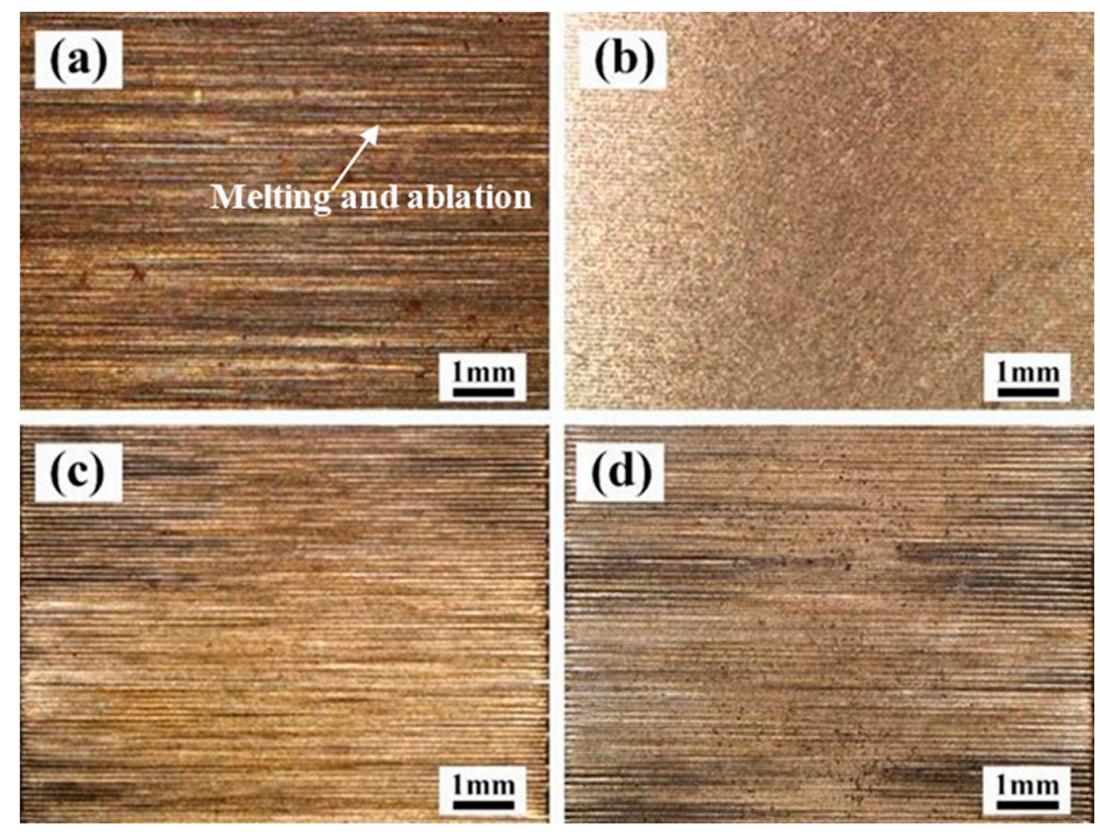

Figure 5. The effect of laser Y-moving speed on the macro morphology of the cleaned surface. (a) $5 \mathrm{~mm} / \mathrm{s}$; (b) $7 \mathrm{~mm} / \mathrm{s}$; (c) $9 \mathrm{~mm} / \mathrm{s}$; (d) $11 \mathrm{~mm} / \mathrm{s}$ at X-scanning speed of $1500 \mathrm{~mm} / \mathrm{s}$.
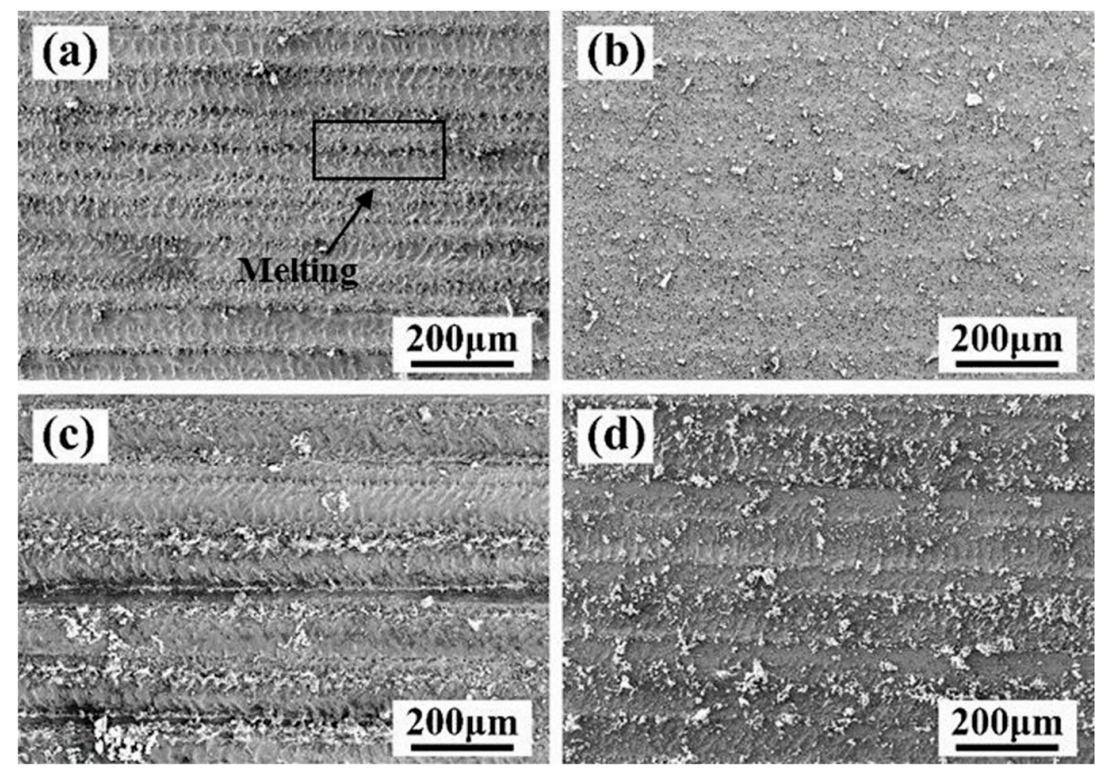

Figure 6. The effect of laser Y-moving speed on the micro-morphology of the cleaned surface. (a) $5 \mathrm{~mm} / \mathrm{s}$; (b) $7 \mathrm{~mm} / \mathrm{s}$; (c) $9 \mathrm{~mm} / \mathrm{s}$; (d) $11 \mathrm{~mm} / \mathrm{s}$ at laser X-scanning speed of $1500 \mathrm{~mm} / \mathrm{s}$.

\subsection{Distribution of Element on the Surface of the Cleaned Material}

In order to further confirm the cleaning effect, it is also necessary to characterize the element analysis, such as the contents of Fe (main element in base metal) and $\mathrm{C}$ (main element in paint), on the cleaned surface.

\subsubsection{The Effect of Laser X-Scanning Speed}

Figure 7 reports the results of the map scanning of the EDS of the cleaned surface at different X-scanning speeds when the Y-moving speed is $7 \mathrm{~mm} / \mathrm{s}$. By comparison of the distribution of Fe element, at the relatively low X-scanning speed, like $500 \mathrm{~mm} / \mathrm{s}$ and $1000 \mathrm{~mm} / \mathrm{s}$, lots of band-shaped traces with light yellow could be observed, as shown in Figure 7a,b. With increasing the X-scanning speed further, 
the band-shaped traces disappeared and light-yellow points distributed on the surface, as shown in Figure 7c,d. In case of the distribution of C element, some band-shaped traces with deep blue distributed loosely on the surface at the X-scanning speeds of $500 \mathrm{~mm} / \mathrm{s}$ and $1000 \mathrm{~mm} / \mathrm{s}$, as shown in Figure 7e,f. However, the deep blue appeared in terms of point distributions, and the points were relatively small at a X-scanning speed of $1500 \mathrm{~mm} / \mathrm{s}$, comparing with that of $2000 \mathrm{~mm} / \mathrm{s}$, as shown in Figure $7 \mathrm{~g}$,h. In addition, when the X-scanning speed increased from $500 \mathrm{~mm} / \mathrm{s}$ up to $1500 \mathrm{~mm} / \mathrm{s}$, the Fe content increased from $84 \%$ to the peak value of about $89 \%$; the C content decreased from $13 \%$ to the lowest value of about $9 \%$, as can be seen in Figure 8.

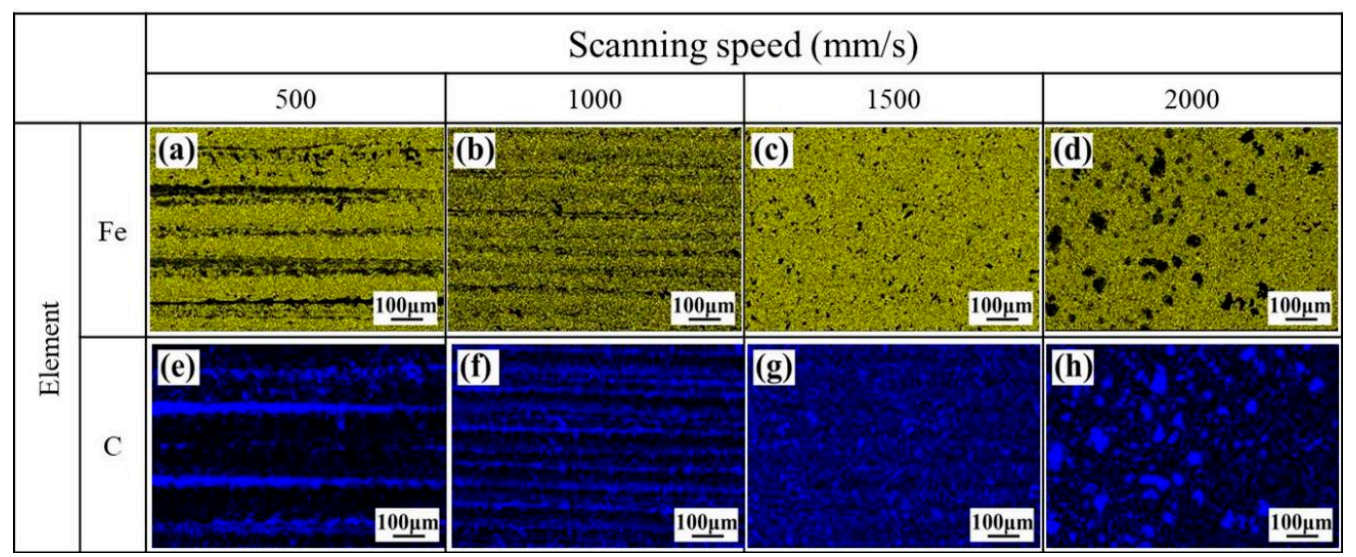

Figure 7. The effect of laser $X$-scanning speed on the distribution of the elements of the cleaned surface. (a) Fe, at $500 \mathrm{~mm} / \mathrm{s}$; (b) Fe, at $1000 \mathrm{~mm} / \mathrm{s}$; (c) Fe, at $1500 \mathrm{~mm} / \mathrm{s}$; (d) Fe, at $2000 \mathrm{~mm} / \mathrm{s}$; (e) C, at $500 \mathrm{~mm} / \mathrm{s}$; (f) C, at $500 \mathrm{~mm} / \mathrm{s} ;(\mathrm{g}) \mathrm{C}$, at $500 \mathrm{~mm} / \mathrm{s} ;$ (h) C, at $500 \mathrm{~mm} / \mathrm{s}$.

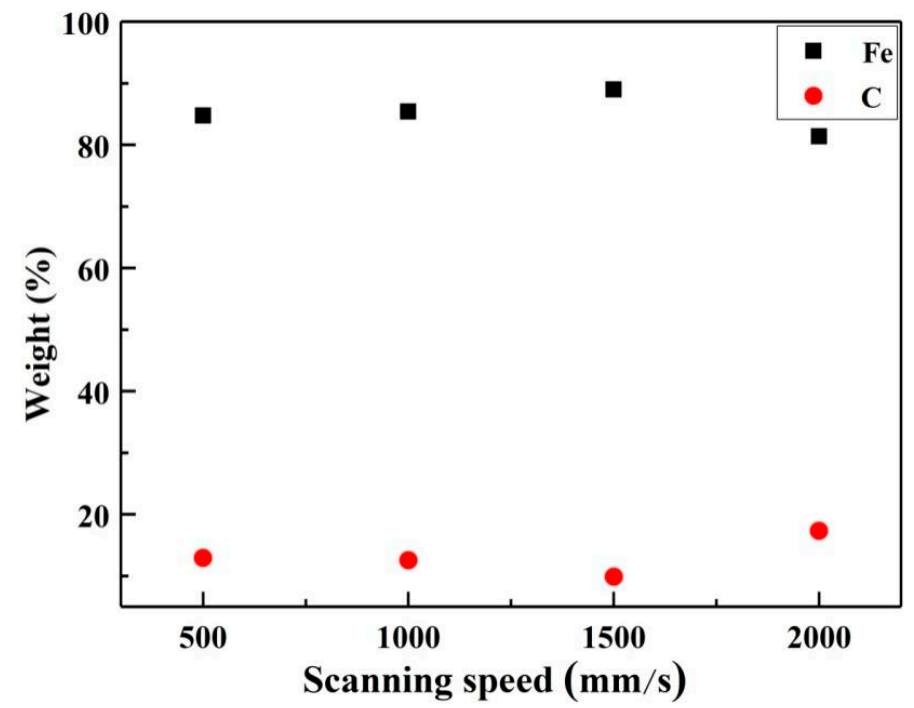

Figure 8. The effect of laser X-scanning speed on the contents of the elements of the cleaned surface.

When the X-scanning speed was relatively small, the scanning path with the band-shaped distribution could be observed easily. Most of the paints were removed, however, some remained in the edge area, leading to the occurrence of low content of Fe and high content of C. Meanwhile, the increased $X$-scanning speed can reduce the time of radiation per unit area. Thus, the scanning path disappeared and Fe elements distributed uniformly on the cleaned surface. The X-scanning speed further increased and the radiation per unit time was insufficient, leading to the appearance of large residual paint. 


\subsubsection{The Effect of Laser Y-Moving Speed}

Figure 9 presents the results of the map scanning of the EDS of the cleaned surface at different Y-moving speeds when the X-scanning speed is $1500 \mathrm{~mm} / \mathrm{s}$. By comparison of the distribution of Fe element, at relatively low Y-moving speed, like $5 \mathrm{~mm} / \mathrm{s}$ and $7 \mathrm{~mm} / \mathrm{s}$, light yellow appeared in terms of point distributions, as shown in Figure 9a,b. With the Y-moving speed increased, yellow band-shaped traces appeared, as shown in Figure 9c,d. In case of the distribution of $C$ element, the deep blue appeared in terms of point distributions, and the points were relatively sparse at a X-scanning speed of $7 \mathrm{~mm} / \mathrm{s}$, compared with that of $5 \mathrm{~mm} / \mathrm{s}$, could be observed in Figure 9e,f. However, some band-shaped traces with deep blue distributed loosely on the surface at the Y-moving speeds of $9 \mathrm{~mm} / \mathrm{s}$ and $11 \mathrm{~mm} / \mathrm{s}$, (Figure $9 \mathrm{~g}$,h). In addition, when the Y-moving speed increased from $5 \mathrm{~mm} / \mathrm{s}$ up to $11 \mathrm{~mm} / \mathrm{s}$, the Fe content decreased from $93 \%$ to the valley value of about $68 \%$ and kept stable, while the C content increased to from $6 \%$ to $27 \%$ and remained unchanged, as can be seen in Figure 10. The increased Y-moving speed can make the time of laser action on the material surface short, thus the residual paint might be melted but not be vaporized, the cleaning path started to appear, and the band-shaped traces of $\mathrm{C}$ and Fe elements distributed on the cleaned surface.

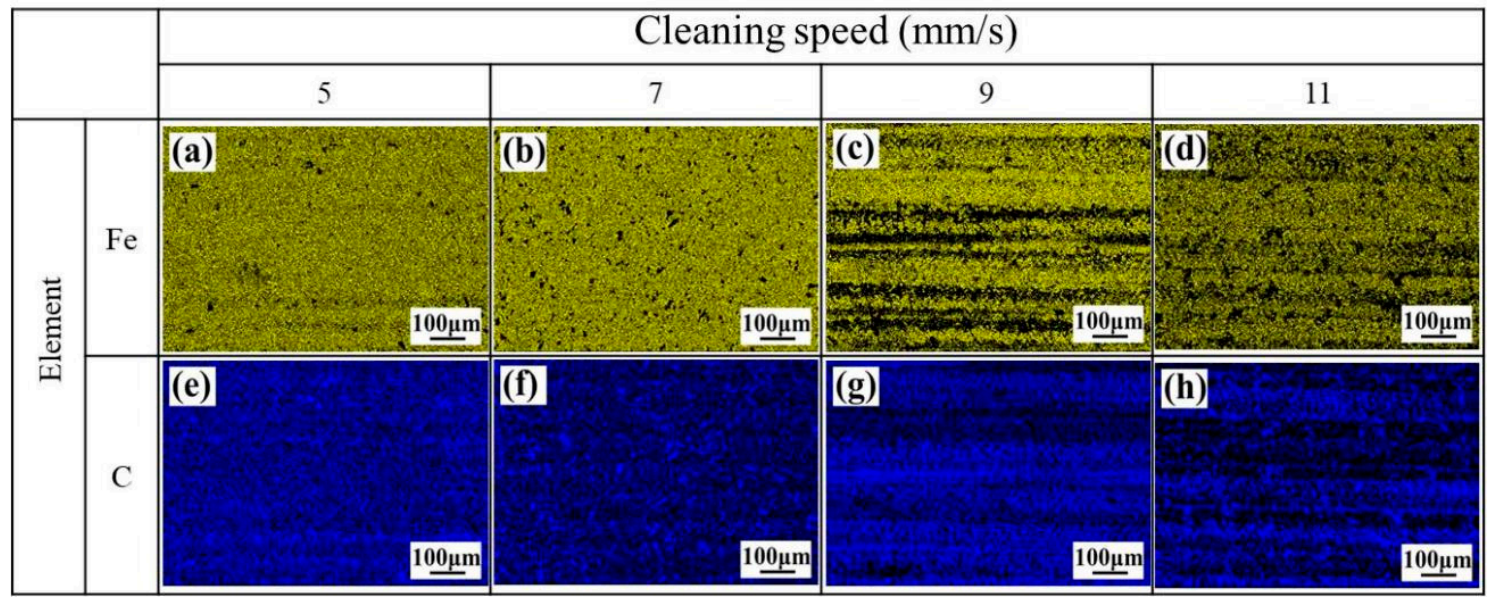

Figure 9. The effect of laser Y-moving speed on the distribution of the elements in the cleaned surface during laser cleaning. (a) Fe, at $5 \mathrm{~mm} / \mathrm{s}$; (b) Fe, at $7 \mathrm{~mm} / \mathrm{s}$; (c) Fe, at $9 \mathrm{~mm} / \mathrm{s}$; (d) Fe, at $11 \mathrm{~mm} / \mathrm{s}$; (e) C, at $5 \mathrm{~mm} / \mathrm{s} ;(\mathbf{f}) \mathrm{C}$, at $7 \mathrm{~mm} / \mathrm{s} ;(\mathbf{g}) \mathrm{C}$, at $9 \mathrm{~mm} / \mathrm{s} ;(\mathbf{h}) \mathrm{C}$, at $11 \mathrm{~mm} / \mathrm{s}$.

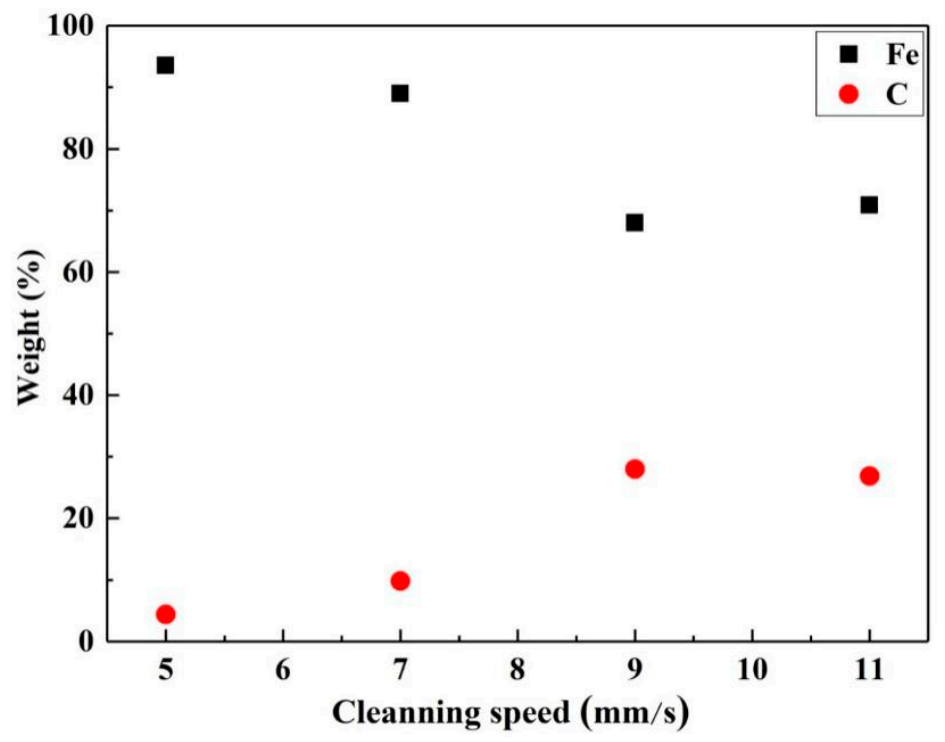

Figure 10. The effect of laser Y-moving speed on the element content in the cleaned surface. 


\subsection{Roughness and Three-Dimensional Topography of the Surface of the Cleaned Material}

In order to reuse the cleaned materials, the base metal should not be damaged, and the surface should meet some roughness requirements after laser cleaning. Therefore, the roughness and three-dimensional topography of the surface of the cleaned material were evaluated.

\subsubsection{The Effect of Laser X-Scanning Speed}

Figure 11 shows the effect of the $X$-scanning speed on the three-dimensional morphology of the cleaned surface at a laser Y-moving speed of $7 \mathrm{~mm} / \mathrm{s}$. When the $X$-scanning speed was $500 \mathrm{~mm} / \mathrm{s}$, there were deep grooves on the surface of the sample, resulting in the surface roughness of $18.4 \mu \mathrm{m}$, as shown in Figure 11a. When the X-scanning speed increased to $1000 \mathrm{~mm} / \mathrm{s}$, the gully traces became shallower, causing a decrease in the roughness, as shown in Figure 11b. While, in case of X-scanning speed of $1500 \mathrm{~mm} / \mathrm{s}$, the traces of the ravines on the cleaned surface disappeared. In addition, a few pits and some small particles presented on the cleaned surface, the roughness of which was as low as $0.5 \mu \mathrm{m}$ in Figure 11c. As can be seen in Figure 11d, at the X-scanning speed of $2000 \mathrm{~mm} / \mathrm{s}$, the size and number of the pits became larger and more, and the size of the convex particles changed to be larger, inducing the occurrence of the roughness of $1.6 \mu \mathrm{m}$.

(a)



(c)

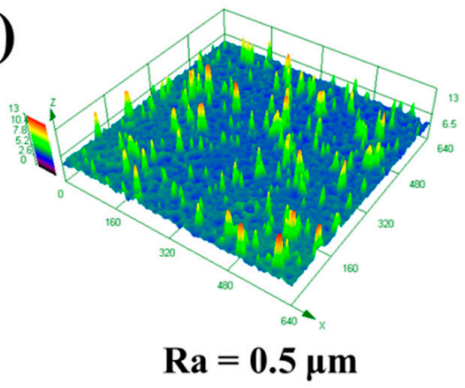

(b)



(d)

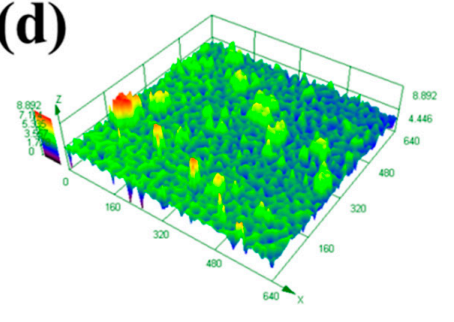

$\mathrm{Ra}=1.6 \mu \mathrm{m}$

Figure 11. The effect of X-scanning speed on the three-dimensional morphology of the cleaned surface: (a) $500 \mathrm{~mm} / \mathrm{s}$ (b) $1000 \mathrm{~mm} / \mathrm{s}$; (c) $1500 \mathrm{~mm} / \mathrm{s}$; (d) $2000 \mathrm{~mm} / \mathrm{s}$ at a laser Y-moving speed of $7 \mathrm{~mm} / \mathrm{s}$.

As the X-scanning speed is low, the laser energy absorbed by the surface of the substrate is relatively larger. Once the paint layer is completely removed, the surface of the substrate will melt and ablate, and the traces will be deeper [16]. As the X-scanning speed increases, the spot overlap effect decreases. Energy absorbed by the material surface is lowered and the material surface is less damaged [26,27], leading to the small roughness of the surface. At the same time, most of the paint on the surface can be removed in this working condition. Meanwhile, the paint layer could not peel off the surface at a higher $\mathrm{X}$-scanning speed.

\subsubsection{The Effect of Laser Y-Moving Speed}

Figure 12 shows the effect of the $X$-scanning speed on the three-dimensional morphology of the cleaned surface at a laser X-scanning speed of $1500 \mathrm{~mm} / \mathrm{s}$. When the Y-moving speed was $5 \mathrm{~mm} / \mathrm{s}$, deep grooves can be observed on the surface of the sample, resulting in the surface roughness of $14 \mu \mathrm{m}$, 
as shown in Figure 12a. As the Y-moving speed increased to $7 \mathrm{~mm} / \mathrm{s}$, deep grooves disappeared and a few pits presented on the cleaned surface, the roughness of which was as low as $0.5 \mu \mathrm{m}$ in Figure $13 \mathrm{~b}$. While, in case of the Y-moving speeds of $9 \mathrm{~mm} / \mathrm{s}$ and $11 \mathrm{~mm} / \mathrm{s}$, the traces of the ravines on the cleaned surface appeared again, and the roughness increased to $3.4 \mu \mathrm{m}$ and $1.8 \mu \mathrm{m}$, respectively, as shown in Figure 12c,d.

(a)



$$
\operatorname{Ra}=14.0 \mu \mathrm{m}
$$

(c)

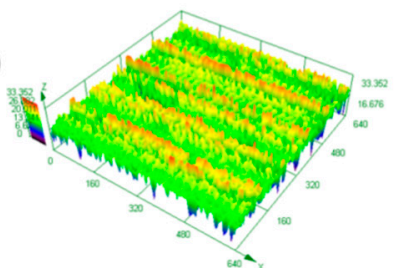

$\mathrm{Ra}=3.4 \mu \mathrm{m}$ (b)

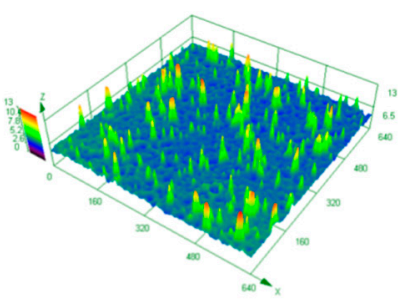

$$
\mathrm{Ra}=0.5 \mu \mathrm{m}
$$

(d)

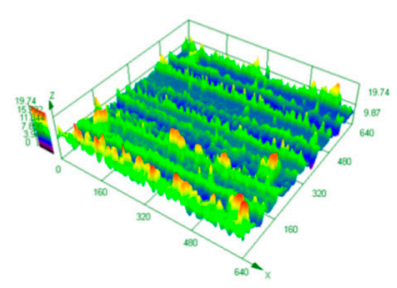

$$
\mathbf{R a}=1.8 \mu \mathrm{m}
$$

Figure 12. The effect of the Y-moving speed on the three-dimensional morphology of the cleaned surface: (a) $5 \mathrm{~mm} / \mathrm{s}$; (b) $7 \mathrm{~mm} / \mathrm{s}$; (c) $9 \mathrm{~mm} / \mathrm{s}$; (d) $11 \mathrm{~mm} / \mathrm{s}$ at the laser X-scanning speed of $1500 \mathrm{~mm} / \mathrm{s}$.
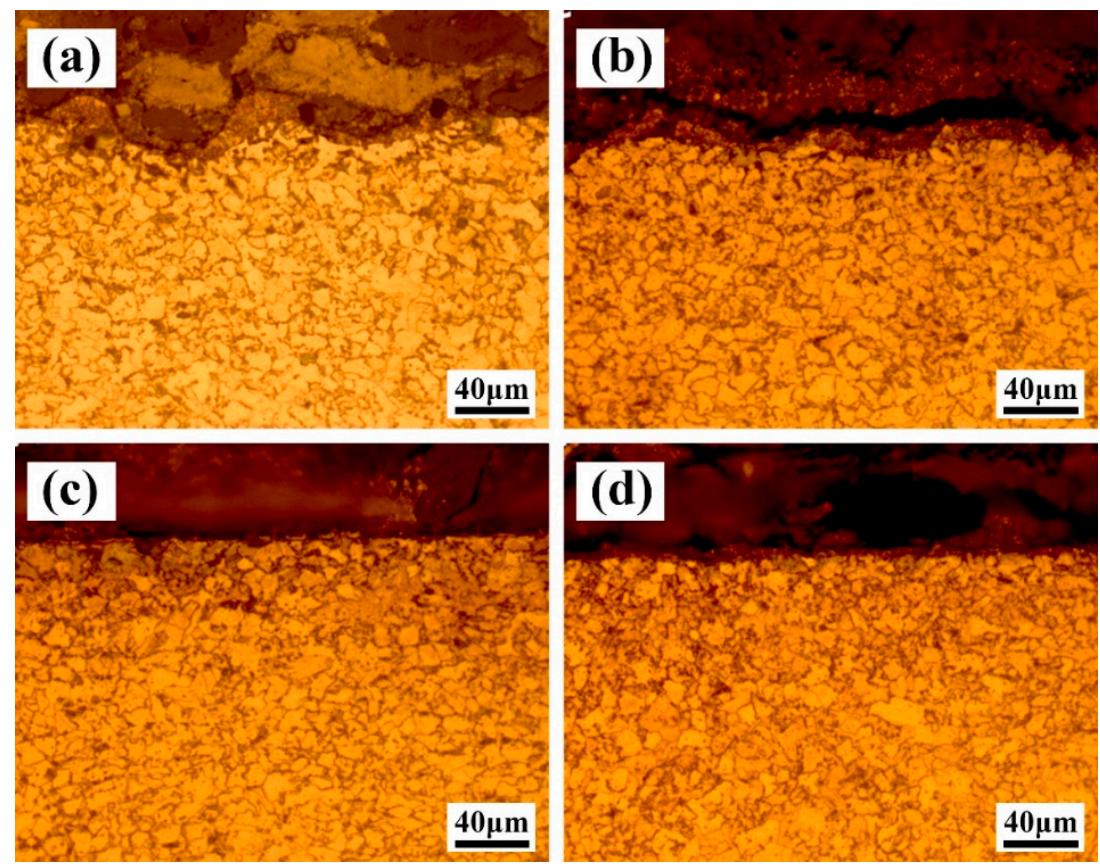

Figure 13. The effect of $X$-scanning speed on the metallographic structure of the cross-section of the Q345 steel (a) $500 \mathrm{~mm} / \mathrm{s}$; (b) $1000 \mathrm{~mm} / \mathrm{s}$; (c) $1500 \mathrm{~mm} / \mathrm{s}$; (d) $2000 \mathrm{~mm} / \mathrm{s}$ at a Y-moving speed of $7 \mathrm{~mm} / \mathrm{s}$ after laser cleaning.

A two-dimensional laser system was employed to clean the paint layer on the surface of the material, and thus the $X$-scanning speed of $X$ direction and the $Y$-moving speed of $Y$ direction plays an important role in the cleaning effect. When the X-scanning speed was too low, the substrate could be damaged. On the contrary, a significant number of the paint could not be cleaned clearly and remained on 
the surface. In addition, a linear residue paint could appear on the edge of the scanning path at a relatively high Y-moving speed [27]. Therefore, the clean effect was better on the condition of the Y-moving speed of $5 \mathrm{~mm} / \mathrm{s}$ and the X-scanning speed of $1500 \mathrm{~mm} / \mathrm{s}$.

\subsection{Microstructure of the Cleaned Region}

During laser cleaning, except for the removal of the paint layer, the substrate could also be affected by the radiation of the laser under a certain condition. Thus, the microstructure and hardness of the cleaned Q345 steel are investigated too after laser cleaning. Figure 13 shows the effect of $X$-scanning speed on the metallographic structure of the cross-section of the steel at a Y-moving speed of $7 \mathrm{~mm} / \mathrm{s}$ after laser cleaning. When the laser X-scanning speed was of $500 \mathrm{~mm} / \mathrm{s}$ and $1000 \mathrm{~mm} / \mathrm{s}$, a fine grain layer around the laser scanning path could been seen in Figure 13a,b. Indicating that the X-scanning speed was $500 \mathrm{~mm} / \mathrm{s}$ the fine grain layer thickness was bigger. However, no obvious fine grain layer was found at the X-scanning speeds of $1500 \mathrm{~mm} / \mathrm{s}$ and $2000 \mathrm{~mm} / \mathrm{s}$ in Figure 13c,d.

Figure 14 reveals that the $\mathrm{X}$-scanning speed had a greater influence on the formation of the microstructure. When the X-scanning speed was $500 \mathrm{~mm} / \mathrm{s}$, the fine grain layer was thicker at peak than valley, as shown in Figure 14a-c. The peak and valley of fine grain layer in case of the $\mathrm{X}$-scanning speed of $1000 \mathrm{~mm} / \mathrm{s}$ was given in Figure $14 \mathrm{~d}-\mathrm{f}$, the fine grain layer became thinner by the comparison of those of $500 \mathrm{~mm} / \mathrm{s}$.
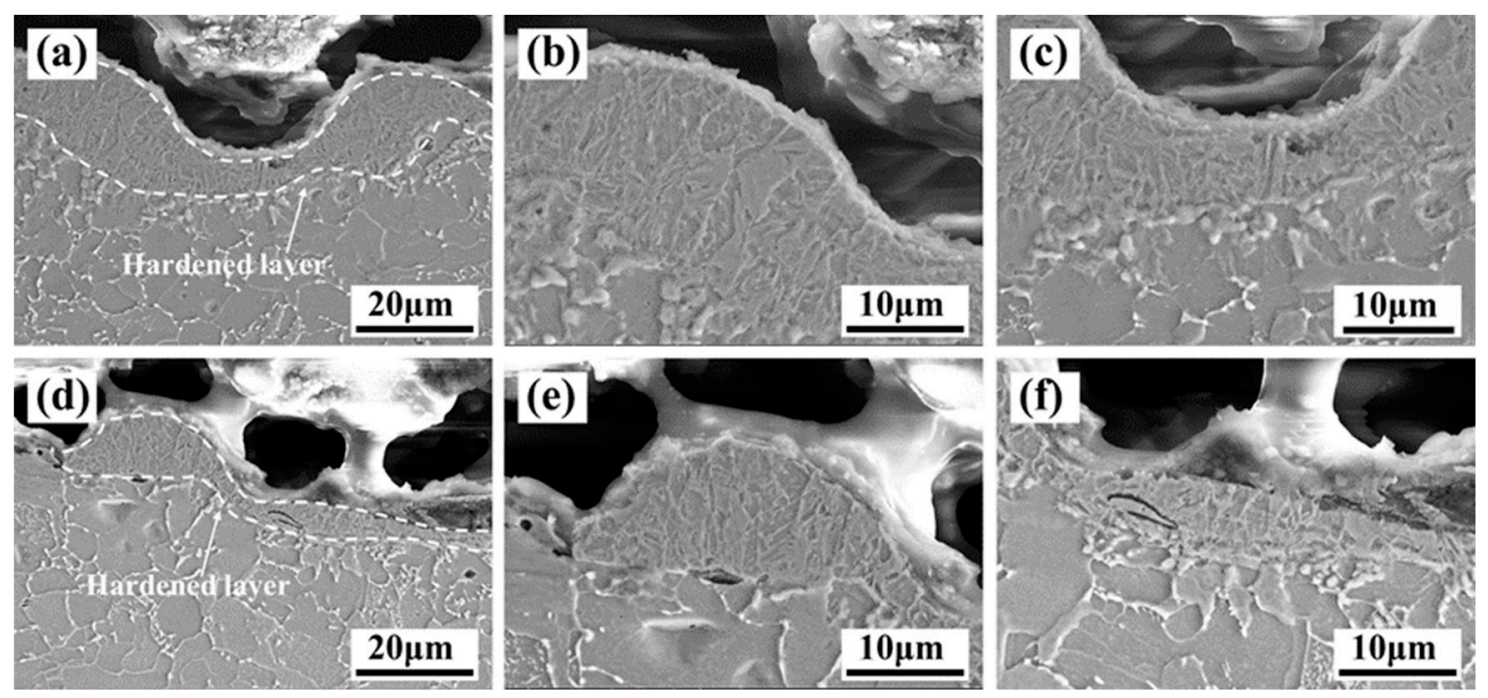

Figure 14. SEM image of the microstructure of the cross-section of the cleaned Q345 steel at a Y-moving speed of $7 \mathrm{~mm} / \mathrm{s}$ and different $X$-scanning speeds after laser cleaning. (a) microstructure at $500 \mathrm{~mm} / \mathrm{s}$; (b) enlarged microstructure of the peak at $500 \mathrm{~mm} / \mathrm{s}$; (c) enlarged microstructure of the valley at $500 \mathrm{~mm} / \mathrm{s}$. (d) microstructure at $1000 \mathrm{~mm} / \mathrm{s}$; (e) enlarged microstructure of the peak at $1000 \mathrm{~mm} / \mathrm{s}$; (f) enlarged microstructure of the valley at $1000 \mathrm{~mm} / \mathrm{s}$.

The formation of the fine grain layer is mainly due to the combined effect of surface melting and shock waves. On the one hand, once the surface of the material absorbs laser energy, the temperature will rise rapidly to reach the melting point of the material, inducing to forming a molten state. It is known that the pulse laser has a shorter action time, the matrix will quickly cool and solidify to form a new structure [28-30]. On the other hand, the pulse laser will generate a high-pressure plasma shock wave after acting on the paint layer. When the shock wave pressure is greater than the elastic limit of the material, the material will undergo plastic deformation and the microstructure will change to form a fine grain layer [31,32]. In addition, the peak part belonged to the middle of two scanning path and accumulate more heat. Thus, the peak part absorbed more laser energy than the valley, resulting in the fine grain layer. In order to further confirm whether the grain size is changed, an EBSD test was performed. When the $\mathrm{X}$-scanning speed of the material was $500 \mathrm{~mm} / \mathrm{s}$, more refined grains could 
be found in the fine grain layer compared with that of a X-scanning speed of $1000 \mathrm{~mm} / \mathrm{s}$, as shown in Figure 15a,b.
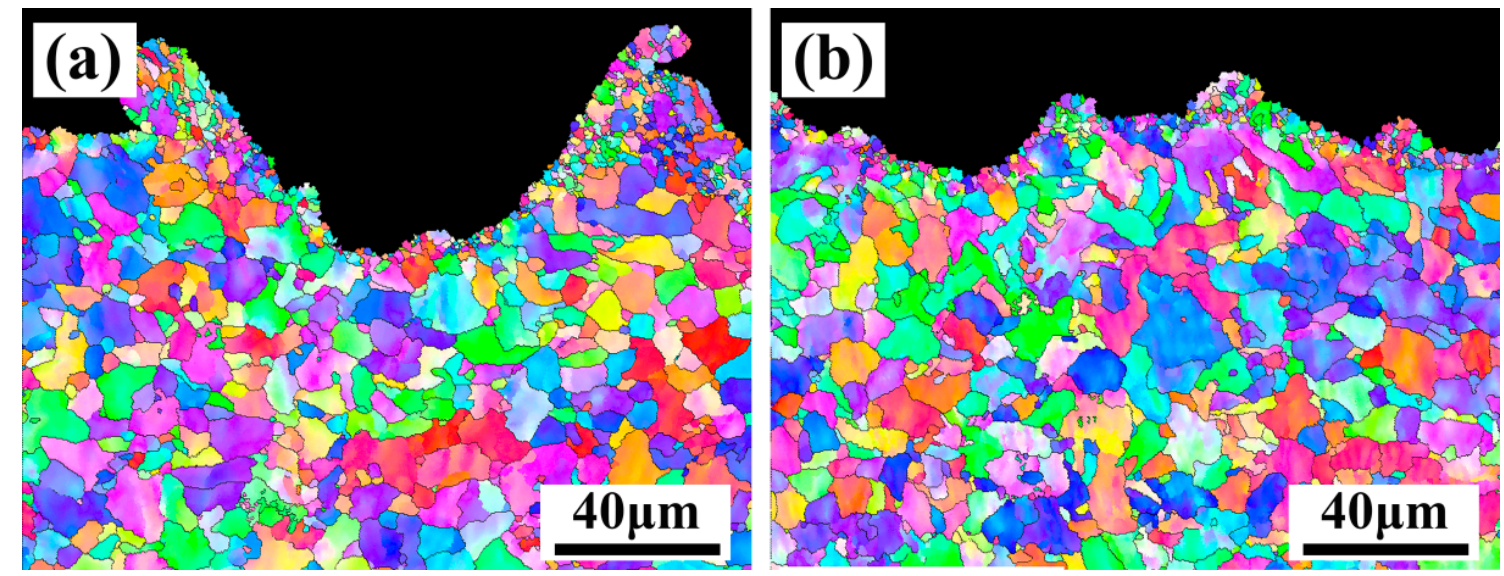

Figure 15. EBSD results at a Y-moving speed of $7 \mathrm{~mm} / \mathrm{s}$ and different $X$-scanning speeds (a) $500 \mathrm{~mm} / \mathrm{s}$; (b) $1000 \mathrm{~mm} / \mathrm{s}$ after laser cleaning.

The morphology of the material surface would also be investigated at the X-scanning speeds of $500 \mathrm{~mm} / \mathrm{s}$ and $1000 \mathrm{~mm} / \mathrm{s}$. OM and SEM images of the morphologies are shown in Figure 16a-d, respectively. The microstructure along the scanning path of the light spot has been significantly refined. The width of the refined layer at a X-scanning speed of $500 \mathrm{~mm} / \mathrm{s}$ was larger and the microstructure was finer than that at $1000 \mathrm{~mm} / \mathrm{s}$. At the low $X$-scanning speed, the radiation per unit area is greater on the surface of the material, leading to larger melting areas. In addition, the plasma shock wave formed after the evaporation of paint layer [26], the laser heat affected area is wider and the grains of which are also finer.
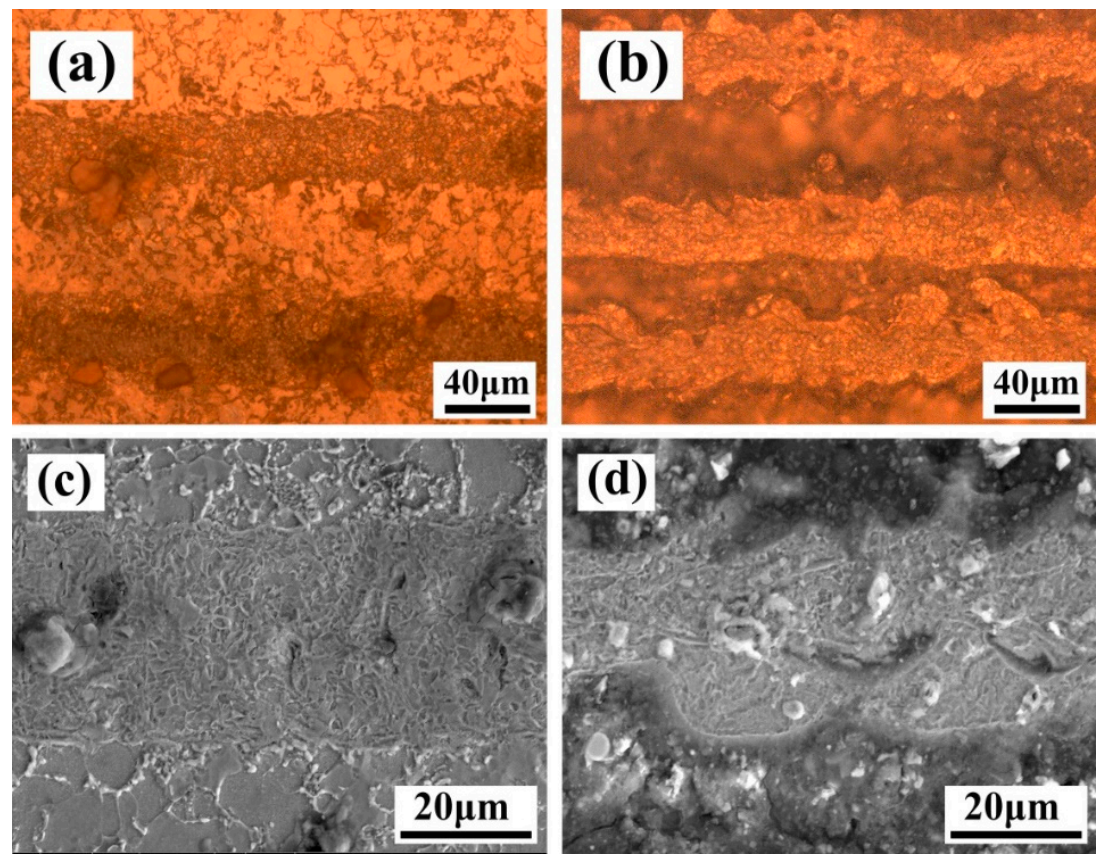

Figure 16. OM and SEM micrographs of the material surface after laser cleaning at different $X$-scanning speed. (a) $500 \mathrm{~mm} / \mathrm{s}(\mathrm{OM})$; (b) $1000 \mathrm{~mm} / \mathrm{s}$ (OM); (c) $500 \mathrm{~mm} / \mathrm{s}$ (SEM); (d) $1000 \mathrm{~mm} / \mathrm{s}$ (SEM). 


\subsection{Hardness of the Fine Grain Layer after Cleaning}

A schematic diagram of the position of the hardness indentation is given in Figure 17a. From the surface, the first two hardness indentation was in the refined layer and others were in the base metal. In Figure 17b, when the X-scanning speeds were $500 \mathrm{~mm} / \mathrm{s}$ and $1000 \mathrm{~mm} / \mathrm{s}$, the hardness of the first point from the surface is the highest, more than $400 \mathrm{HV}$. Then, the hardness of the second point decreased to about $350 \mathrm{HV}$. Meanwhile, in the case of higher X-scanning speeds, the hardness of the first two points from the surface was same as that of base metal, about $200 \mathrm{HV}$. Thus, it can be confirmed that the surface of the material produces a hardened layer at the low $\mathrm{X}$-scanning speed after laser cleaning. The grain refinement makes the dislocation movement more difficult. Grain deformation and slippage becomes difficult, which can resist larger external pressure and lead to the increase of the surface micro-hardness [32,33].
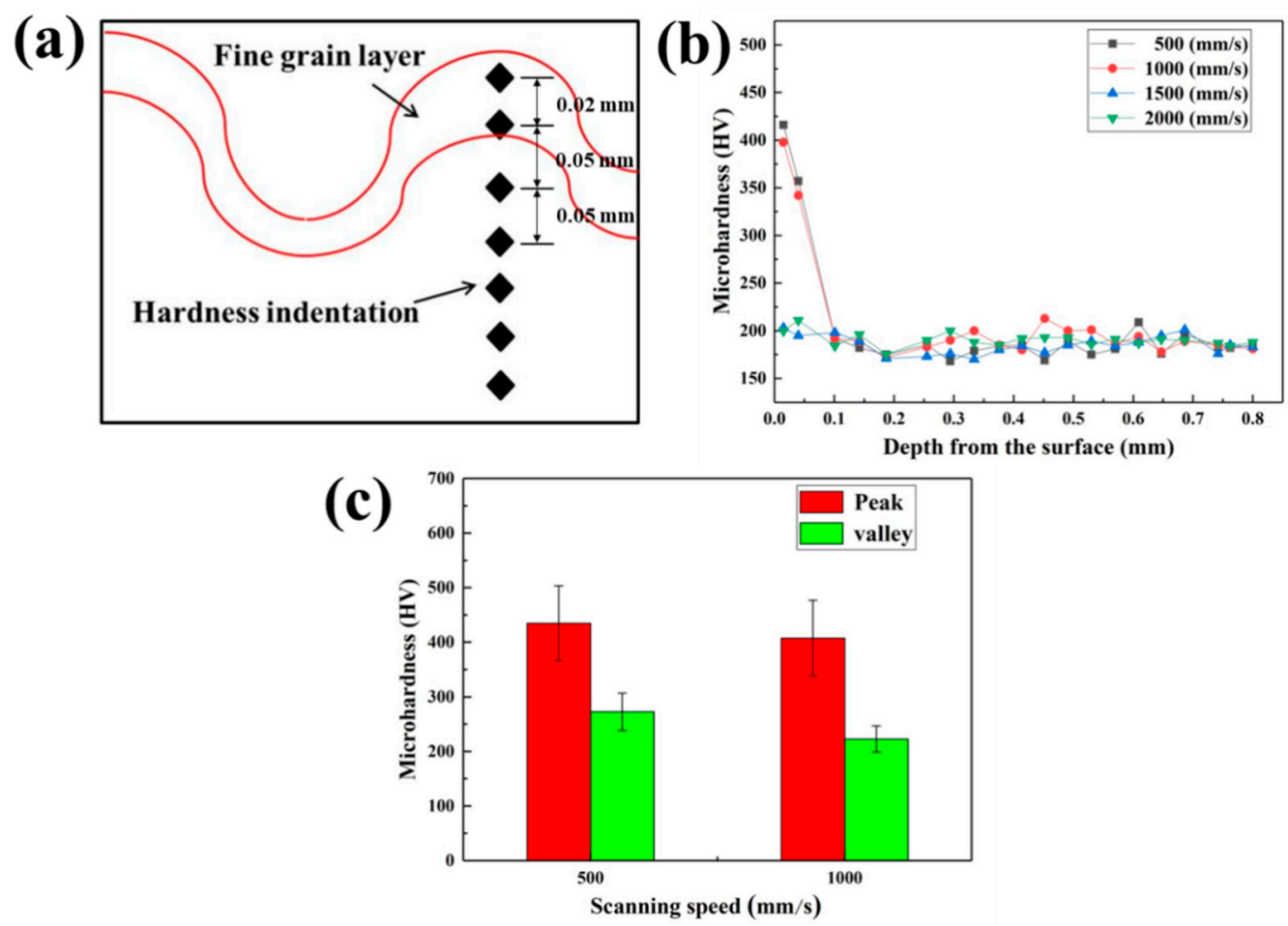

Figure 17. The result of the hardness of the material section. (a) The schematic diagram of the position of the hardness indentation; (b) The effect of X-scanning speed on the hardness of the material section; (c) The result of the hardness of the material section at different position.

In addition, the hardness of the first point of the peak and valley was compared at the X-scanning speeds of $500 \mathrm{~mm} / \mathrm{s}$ and $1000 \mathrm{~mm} / \mathrm{s}$, as shown in Figure 17c. With the near-surface hardness of the material at a X-scanning speed of $500 \mathrm{~mm} / \mathrm{s}$, the hardness at the peak and valley was slightly higher than that at $1000 \mathrm{~mm} / \mathrm{s}$. Regardless which X-scanning speed, the hardness at the peak was higher than those at the valley. At the low X-scanning speed, the radiation per unit area is more on the surface of the material, leading to a rise in the temperature and the plasma shock wave. The formed crystal grains were smaller, and the movement of dislocations was blocked. Greater pressure was required to overcome it, resulting in higher hardness. When the laser spot acts on the surface of the material, the peak part was in the middle of the scanning path of the light spot, resulting in more heat accumulation effect. Therefore, the hardened layer produced was thicker, and the indentation can completely fall into the hardened layer, leading to greater hardness. 


\section{Conclusions}

Laser technology was employed to study the effect of laser X-scanning speed and Y-moving speed on the cleaning effect of Q345 surface paint. The morphology, chemical composition, roughness, microstructure, and hardness of the cleaned material were studied. The conclusions are as follows.

(1) When the Y-moving speed was of $7 \mathrm{~mm} / \mathrm{s}$, the cleaned surface was damaged due to laser radiation of the relatively high energy at the $X$-scanning speeds of $500 \mathrm{~mm} / \mathrm{s}$ and $1000 \mathrm{~mm} / \mathrm{s}$. Then, the content of Fe element on the cleaned surface increased to $89 \%$ and then decreased to about $80 \%$. With increasing X-scanning speed from $500 \mathrm{~mm} / \mathrm{s}$ up to $2000 \mathrm{~mm} / \mathrm{s}$, the roughness declined up to $0.5 \mu \mathrm{m}$ and then had a little promotion.

(2) When the X-scanning speed was equal to $1500 \mathrm{~mm} / \mathrm{s}$, the amount of the residual paint on the cleaned surface tended to increase with increasing Y-moving speed from $5 \mathrm{~mm} / \mathrm{s}$ to $11 \mathrm{~mm} / \mathrm{s}$. This is because the action time of the laser radiation on the surface became short. Meanwhile, the content of Fe element on the cleaned surface had a tendency of firstly decreasing and then remaining constant. Moreover, the roughness reached $0.5 \mu \mathrm{m}$ at a Y-moving speed of $7 \mathrm{~mm} / \mathrm{s}$.

(3) Comprehensively, the cleaning effect of the surface paint could be better on the condition of a X-scanning speed of $1500 \mathrm{~mm} / \mathrm{s}$ and a Y-moving speed of $7 \mathrm{~mm} / \mathrm{s}$ during laser cleaning, since there was no damage, negligible residual paint, and the minimum roughness on the cleaned surface.

(4) A fine grain layer appeared on the cleaned surface after laser cleaning at the $X$-scanning speeds of $500 \mathrm{~mm} / \mathrm{s}$ and $1000 \mathrm{~mm} / \mathrm{s}$, and a Y-moving speed of $7 \mathrm{~mm} / \mathrm{s}$. The maximum hardness of the fine grain layer was two times higher than the base metal, more than $400 \mathrm{HV}$. Moreover, the hardness of the peak of the fine grain layer was larger than those at the valley.

Author Contributions: Conceptualization, X.L. and D.W.; methodology, X.L., D.W., J.G., C.L., W.Z., and N.W.; validation, D.W. and Y.L.; investigation, X.L., D.W., J.G., and W.Z.; writing-original draft preparation, X.L. and D.W.; writing-review and editing, X.L., D.W., J.G., W.Z., C.L., N.W. and Y.L.; supervision, D.W. and Y.L.; project administration, N.W. and D.W.; funding acquisition, D.W. and Y.L. All authors have read and agreed to the published version of the manuscript.

Funding: This research was funded by the National Natural Science Foundation of China (Grant No: 51705219), the Foundation of Key Laboratory of Green Ship Technology of Jiangsu Province (Grant No: 2019Z11), the Science Foundation of Senior Talents of Jiangsu University (Grant No: 17JDG039), the Students Practice Innovation Training Program Project of Jiangsu University (Grant No: 201910299188Y), the Students Research Project of Jiangsu University (Grant No: 18A022).

Acknowledgments: The authors would like to thank Jiangsu Dingtai Engineering Materials Co. Ltd. for technical and funding supports. The authors would also like to thank Liju Zhou and Liting Yang who did the methodology and investigation of the experiment in School of Materials Science and Engineering in Jiangsu University.

Conflicts of Interest: The authors declare no conflict of interest.

\section{References}

1. Zhang, Y.; Long, B.; Meng, K.; Gohkman, A.; Zhang, Z. Diffusion bonding of Q345 steel to zirconium using an aluminum interlayer. J. Mater. Process. Tech. 2019, 275, 2-4. [CrossRef]

2. Li, S.; Wang, Q.R.; Li, X.L.; Tian, J.B. Seismic performance of Y-Type eccentrically braced frames combined with high—strength steel based on performance-based seismic design. Struct. Des. Tall. Spec. 2020, 29, 4-6. [CrossRef]

3. Lv, H.; Gou, G.; Fu, Z.; Gao, W. Stress corrosion property of 304 stainless steel and Q345 steel laser-mag hybrid welded joints. Int. J. Mod. Phys. B 2019, 34, 2040057. [CrossRef]

4. Gerhard, S.; Werner, L. Industrial 2-kW TEA $\mathrm{CO}_{2}$ laser for paint stripping of aircraft. Proc. SPIE 1995, 2502, 57-62. [CrossRef]

5. Gomes, V.; Dionísio, A.; Pozo-Antonio, J.S.; Rivas, T.; Ramil, A. Mechanical and laser cleaning of spray graffiti paints on a granite subjected to a $\mathrm{SO}_{2}$-rich atmosphere. Constr. Build. Mater 2018, 188, 621-632. [CrossRef]

6. Feng, C.; Zhang, Y.; Liu, J.; Qian, Y.; Zhang, J.; Zhao, J.; Shi, F.; Bai, X. Optimized chemical cleaning procedure for enhancing photoemission from GaAs photocathode. Mat. Sci. Semicon. Proc. 2019, 91, 41-46. [CrossRef] 
7. Tangsopa, W.; Thongsri, J. Development of an industrial ultrasonic cleaning tank based on harmonic response analysis. Ultrasonics 2019, 91, 68-76. [CrossRef]

8. Bañon, F.; Sambruno, A.; Batista, M.; Simonet, B.; Salguero, J. Surface Quality and Free Energy Evaluation of s275 Steel by Shot Blasting, Abrasive Water Jet Texturing and Laser Surface Texturing. Metals 2020, 10, 290. [CrossRef]

9. Rudawska, A.; Danczak, I.; Müller, M.; Valasek, P. The Effect of Sandblasting on Surface Properties for Adhesion. Int. J. Adhes. 2016, 70, 176-190. [CrossRef]

10. Harada, T.; Spence, S.; Margiolakis, A.; Deckoff-Jones, S.; Ploeger, R.; Shugar, A.N.; Hamm, J.; Dani, K.M.; Dani, A.R. Obtaining cross-sections of paint layers in cultural artifacts using femtosecond pulsed lasers. Materials 2017, 10, 107. [CrossRef]

11. Chen, Y.; Deng, G.L.; Zhou, Q.; Feng, G. Acoustic signal monitoring in laser paint cleaning. Laser Phys. 2020, 30, 2-4. [CrossRef]

12. Chen, G.X.; Kwee, T.J.; Tan, K.P.; Choo, Y.S.; Hong, M.H. Laser cleaning of steel for paint removal. Appl. Phys. A 2010, 101, 249-253. [CrossRef]

13. Al-Rousan, R.Z.; AL-Tahat, M.F. Consequence of Surface Preparation Techniques on the Bond Behavior Between Concrete and CFRP Composites. Constr. Build. Mater. 2019, 212, 362-374. [CrossRef]

14. Liu, X.; Du, D.; Mourou, G. Laser Ablation and Micromachining with Ultrashort Laser Pulses. IEEE J. Quantum Elect. 1997, 33, 1706-1716. [CrossRef]

15. Ancona, A.; Carbone, G.; De Filippis, M.; Volpe, A.; Lugarà, P.M. Femtosecond laser full and partial texturing of steel surfaces to reduce friction in lubricated contact. Adv. Opt. Technol. 2014, 3, 539-547. [CrossRef]

16. Rode, A.V.; Freeman, D.; Baldwin, K.G.H.; Wain, A.; Uteza, O.; Delaporte, P. Scanning the laser beam for ultrafast pulse laser cleaning of paint. Appl. Phys. A 2008, 93, 135-139. [CrossRef]

17. Kumar, M.; Bhargava, P.; Biswas, A.K.; Sahu, S.; Mandloi, V.; Ittoop, M.O.; Khattak, B.Q.; Tiwari, M.K.; Kukreja, L.M. Epoxy-Paint stripping using TEA $\mathrm{CO}_{2}$ laser: Determination of threshold fluence and the process parameters. Opt. Laser Technol. 2013, 46, 29-36. [CrossRef]

18. Zhao, H.; Qiao, Y.; Du, X.; Wang, S.; Liu, X. Laser cleaning performance and mechanism in stripping of polyacrylate resin paint. Appl. Phys. A 2020, 126, 10-14. [CrossRef]

19. Barletta, M.; Gisario, A.; Tagliaferri, V. Advance in paint stripping from aluminum substrates. J. Mater. Process. Tech. 2006, 173, 232-239. [CrossRef]

20. Watkins, K.G.; Chen, X.; Fujioka, T.; Matsunawa, A. Mechanisms of laser cleaning. Proc. SPIE 2000, 3888, 165-174. [CrossRef]

21. Shamsujjoha, M. Effects of laser ablation coating removal (LACR) on a steel substrate: Part 1: Surface profile, microstructure, hardness, and adhesion. Surf. Coat. Technol. 2015, 281, 193-205. [CrossRef]

22. Shi, T.; Wang, C.; Mi, G.; Yan, F. A study of microstructure and mechanical properties of aluminum alloy using laser cleaning. J. Manuf. Process. 2019, 42, 60-66. [CrossRef]

23. Zhao, W.Q.; Liu, H.D.; Shen, X.W.; Wang, L.Z.; Mei, X.S. Percussion drilling hole in Cu, Al, Ti and Ni alloys using ultra-short pulsed laser ablation. Materials 2020, 13, 31. [CrossRef] [PubMed]

24. Ma, M.; Wang, L.; Li, J.; Jia, X.; Zhou, Y. Investigation of the surface integrity of Q345 steel after Nd:YAG laser cleaning of oxidized mining parts. Coatings 2020, 10, 716. [CrossRef]

25. Li, X.; Zhang, Q.; Zhou, X.; Zhu, D.; Liu, Q. The influence of nanosecond laser pulse energy density for paint removal. Optik 2018, 156, 841-846. [CrossRef]

26. Gregorčič, H.P.; Conradi, M.; Hribar, L.; Hočevar, M. Long-term influence of laser-processing parameters on (Super) hydrophobicity development and stability of stainless-steel surfaces. Materials 2018, 11, 2240. [CrossRef]

27. Zhang, Z.Y.; Zhang, J.Y.; Wang, Y.B.; Zhao, S.S.; Lin, X.C.; Li, X.Y. Removal of paint layer by layer using a $20 \mathrm{kHz} 140 \mathrm{Ns}$ quasi-continuous wave laser. Optik 2018, 174, 46-55. [CrossRef]

28. Mahanty, S.; Gouthama. Surface modification of Al-Si alloy by excimer laser pulse processing. Mater. Chem. Phys. 2016, 173, 192-199. [CrossRef]

29. Leone, C.; Papa, I.; Tagliaferri, F.; Lopresto, V. Investigation of CFRP laser milling using a 30W Q-switched Yb:YAG fiber laser: Effect of process parameters on removal mechanisms and HAZ formation. Compos. Part A Appl. Ence Manuf. 2013, 55, 129-142. [CrossRef]

30. Vasant, J.A.; Gopi, G.; Jegaraj, J.J.R.; Kumar, K.R.; Oyyaravelu, R. Finite element simulation and experimental validation of laser assisted machining of Inconel 718. Mater. Today 2018, 5, 13637-13649. [CrossRef] 
31. Król, M.; Snopiński, P. Selective laser melting of 18NI-300 maraging steel. Materials 2020, 13, 4268. [CrossRef] [PubMed]

32. Liu, K.K.; Hill, M.R. The effects of laser peening and shot peening on fretting fatigue in Ti-6Al-4V Coupons. Tribol. Int. 2009, 42, 1250-1262. [CrossRef]

33. Montross, C.S.; Wei, T.; Ye, L.; Clark, G.; Mai, Y.W. Laser shock processing and its effects on microstructure and properties of metal alloys: A Review. Int. J. Fatigue 2002, 24, 1021-1036. [CrossRef]

Publisher's Note: MDPI stays neutral with regard to jurisdictional claims in published maps and institutional affiliations.

(C) 2020 by the authors. Licensee MDPI, Basel, Switzerland. This article is an open access article distributed under the terms and conditions of the Creative Commons Attribution (CC BY) license (http://creativecommons.org/licenses/by/4.0/). 